\title{
Implantación del Plan de Calidad en la Comunidad de Madrid (1995-1998)
}

\section{José Luis Moreno Casas*}

\section{Creación de la unidad impulsora de la implantación}

La Dirección General de Calidad de los Servicios se creó en julio de 1995 por Decreto del Consejo de Gobierno de la Comunidad de Madrid. Se trata de una unidad de consultoría interna, dependiente de la Consejería de Hacienda, que tiene como objetivo principal obtener mejoras concretas en la gestión pública colaborando con el resto de unidades del Gobierno Regional.

En la actualidad esta unidad cuenta con cuatro servicios, inspección, evaluación interna, seguimiento de la calidad y consultoría de gestión, en los que desarrollan sus actividades un equipo humano de profesionales, funcionarios de carrera con experiencia probada como consultores y analistas de organización, en las principales áreas de actividad de la Administración autonómica.

El equipo de consultores (20 titulados superiores y 5 administrativos) trabaja por dar respuesta a las necesidades planteadas tanto por los clientes externos, ciudadanos, como a las planteadas por las diferentes unidades, clientes internos, de la Comunidad de Madrid y todo ello con el mínimo coste posible, de forma que sus prestaciones puedan ser competitivas con las ofrecidas por el Sector Privado.

La Dirección General de Calidad de los Servicios facilita a lós Centros Directivos de la Comunidad de Madrid la introducción de metodologías y herramientas de calidad que permitan mejorar la prestación de los servicios. Asimismo esta unidad apoya a los Centros directivos en la definición de sus clientes y en la incorporación de las demandas de los ciudadanos a sus procesos de gestión. Analiza el ajuste de la gestión pública autonómica a los estándares de calidad fijados en colaboración con las diferentes unidades responsables de la producción de servicios públicos.

Los principales tipos de trabajos realizados por los consultores de la Dirección General de Calidad de los Servicios son los siguientes:

- Estudios operativos y estudios organizativos.

- Diseño y rediseño de estructuras organizativas y servicios.

- Gestión del cambio a través de la participación y de la formación.

- Evaluaciones informáticas, implantación de sistemas y busqueda de software.

- Análisis de procesos y rediseño de procedimientos administrativos.

- Evaluaciones Internas siguiendo el Modelo Europeo de Excelencia.

- Supervisión de actividades y servicios a través de encuestas y visitas de inspección.

- Desarrollo de Planes de Ahorro y normalización de instrucciones y de impresos.

El ciclo de vida de un proyecto se inicia tras la petición realizada por el Consejo de Gobierno (Proyectos corporativos) o de alguno de los 60 clientes/Altos Cargos de la Comunidad de Madrid (Proyectos singulares). Tras una primera reunión de trabajo y toma de datos se presenta una propuesta de colaboración que presenta la metodología, el equipo de trabajo, el calendario 
concreto para dicha actuación y la carta de aceptación de la propuesta.

El Alto Cargo devuelve en su caso la carta de aceptación que faculta al equipo de trabajo para iniciar el proyecto, que es realizado por un equipo mixto formado tanto por personal de la unidad de Calidad de los Servicios como por personal de la unidad sobre la que se actúa. Tras las coriespondientes reuniones de seguimiento, la presentación de los resultados finales correrá a cargo del equipo que realice el estudio y siempre ante el equipo directivo de la unidad que requirió nuestros servicios.

El proyecto se da por terminado cuando se reciban las respuestas al cuestionario de evaluación de la calidad de los trabajos, donde el Alto Cargo que solicitó nuestra colaboración evalúa 10 atributos (valoración e importancia), información básica para conocer el grado de satisfacción de nuestros clientes con los servicios que les ofrecemos.

Durante la vida del proyecto, se realiza un seguimiento mensual de las horas que cada miembro del equipo de trabajo está imputando a cada proyecto, por lo que es posible realizar un seguimiento del coste por proyecto, así como del nivel de ocupación del personal de la unidad. Este seguimiento de la cargabilidad y de la realización de los proyectos se hace informáticamente a través de la aplicación SCP (Seguimiento del Coste de Proyectos) desarrollada en la propia unidad.

Anualmente se afrontan más de 60 proyectos diferentes con una inversión superior a las 36.000 horas, lo que supone un coste cercano a los 220 millones de pesetas (gastos de personal y servicios).

Con respecto al tipo de personal que desarrolla estas actividades, todos ellos son funcionarios de carrera, Licenciados en Derecho, Ciencias Empresariales, Sociología o Ingenieros.

En un estudio sobre Gestión del Conocimiento y Capital Intelectual de la unidad, realizado en junio de 1998 por KPMG, se destacaron como factores mejor posicionados de la unidad frente a la media muestral (obtenida en el Proyecto Logos, con una muestra de 250 empresas españolas), los siguientes:

- Liderazgo abierto al entorno.

- Líderes aprendedores.

- Elevado aprendizaje de la experiencia organizacional.

- Conocimiento de las capacidades de la unidad.

- Diseño de equipos abiertos.

- Colaboración con otros agentes.

- Compartir el conocimiento y la información.

Esta información nos facilita el perfil del personal que desarrolla los proyectos de calidad en el seno de la Dirección General de Calidad de los Servicios.

\section{Elementos del Plan de Calidad de la Comunidad de Madrid}

La implantación en la Comunidad de Madrid de un Plan de Calidad Total en los servicios públicos es uno de los compromisos principales del actual Gobierno de Madrid, con este compromiso se pretende lograr el objetivo de dotar al ciudadano de nuestra Región de un mayor poder de decisión como consumidor individual de servicios públicos.

En este sentido, el compromiso de nuestro Gobierno es conseguir la participación y colaboración de los empleados públicos en la mejora de la calidad de los servicios que prestamos, con el fin de obtener la satisfacción de los ciudadanos, la rentabilidad de la organización y los beneficios para nuestros empleados de acuerdo con las exigencias de la sociedad en general.

El proceso de implantación de dicho Plan se está apoyando en los siguientes puntos:

1.9) La definición del ciudadano de Madrid como un cliente cargado de derechos para nuestra Administración. El ciudadano debe ser transformado en un consumidor individual de servicios públicos. La Comunidad de Madrid es una organización prestadora de servicios (1500 servicios prestados por 80 grandes unidades). Hemos establecido como misión corporativa la satisfacción de las necesidades de los ciudadanos.

2.) El establecimiento de nuestro compromiso público de mejora continua y de ofrecer unos servicios públicos de calidad mediante el desarrollo de más de 150 proyectos para mejorar el funcionamiento interno de la Administración regional. En todos los proyectos se fomenta la participación de los empleados públicos y de los ciudadanos tanto en la fase de diseño, de implantación y de evaluación.

3.. ) La existencia de una normativa específica que regula estas materias a través de la necesaria elaboración de Cartas de Servicios o "contratos concretos de calidad", del establecimiento del Modelo Europeo de Excelencia y la convocatoria anual de los Premios a la Excelencia y Calidad de los Servicios Públicos de Madrid como mecanismo para hacer aflorar nuestras mejores prácticas.

Algunas de las principales acciones de soporte que han apoyado el proceso de implantación del Plan de Calidad han sido las siguientes:

- Dotación de recursos cualificados para el impulso de los proyectos de calidad mediante la creación de una unidad 
específica dependiente de la Consejería de Hacienda en la que actualmente trabajan 25 personas.

- Definición de los tres ejes clave en Calidad: Directivos (Altos Cargos y Jefes de Servicio), mandos intermedios y primera linea de contacto con el ciudadano, estableciendo acciones específicas para cada grupo. Diseño de programas formativos a medida de cada uno de los grupos indicados.

- Compromiso claro y explícito del equipo directivo, el Consejo de Gobierno de la Comunidad de Madrid, con la Calidad Total y la mejora contina.

- Desarrollo de Cartas de Servicios y Estatutos Sectoriales (Decálogo de Derechos del Ciudadano, Estatuto del Paciente, Estatuto del Contribuyente, ...) , mediante el fomento de la participación de directivos y empleados públicos.

- Cálculo periódico del Índice de Percepción de Calidad de los Servicios (IPCS) tanto en las áreas de atención al ciudadano como en los principales servicios públicos.

- Convocatoria anual de los Premios a la Excelencia y Calidad en los servicios públicos regulado por el Decreto 27/1997 como método para hacer aflorar las mejores prácticas y transmitir el conocimiento internamente.

- Elección del Modelo Europeo de Excelencia como referente para la realización de las Evaluaciones Internas, tradicionalmente Inspecciones Operativas de Servicios (IOS).

- Reforma y mejora de las principales Oficinas de la Red de Información y Atención al Ciudadano. Fomento de la accesibilidad y transparencia de la información regional a disposición de los ciudadanos mediante el uso de tecnologías de información.

- Colaboración plena con otras Administraciones y apoyo a la constitución de una Red de Calidad de las Administraciones Públicas (soportada en acciones de la Asociación Española de Calidad y del Club Gestión de Calidad). Realización de actividades de Benchmarking e intercambio de experiencias con otras organizaciones públicas y privadas.

- Participación de la Comunidad de Madrid en los Foros especializados de Calidad. Firma de diversos Convenios de colaboración con otras organizaciones públicas y privadas en materia de calidad y mejora del servicio al ciudadano.

Para lograr una mayor eficacia en la implantación del Plan de Calidad en la Comunidad de Madrid, se ha ido aprobando una regulación especifica compuesta por Decretos y Órdenes.
Además de los Decretos de creación (84/1995) y de desarrollo de funciones (113/1997) de la unidad, el.Gobierno Regional aprobó en Marzo de 1997, el Decreto 27/1997 por el que se regulan lá necesania evaluacioún de los servicios púbiicos regionáles utilizando el Modelo Europeo de Excelencia, la comunicación de los compromisos con el ciudadano a través de las Cartas de Servicios y la convocatoria anual del Premio a la Excelencia y Calidad de Servicio Público.

Durante 1998 el Consejo de Gobierno aprobó el Decreto 44/1998 que regula en profundidad la preparación y aprobación de Cartas de Servicios.

Por su parte, el Consejero de Hacienda Antonio Beteta, en este período de tiempo ha dictado las Órdenes 819/1997 y 2381/1997, regulando la realización de trabajos de imprenta de acuerdo con las directrices del Plan de Ahorro y la identificación del personal de atención al ciudadano. Las Órdenes 1049/1997 y $1417 / 1998$ por su parte regulan la primera y segunda Convocatoria del Premio a la Excelencia y Calidad.

Finalmente en julio de 1998 la Orden 1895/1998 dio publicidad a los principales derechos de los Contribuyentes de la Comunidad de Madrid, en el marco de la Ley 1/1998, de 26 de febrero, de Derechos y Garantías de los Contribuyentes, así como el modelo de impreso que permite iniciar el procedimiento de solicitud de valoración previa de un bien.

\section{Principales proyectos corporativos}

\subsection{Escuchar la voz del cliente: cálculo periódico del Índice de Percepción de Calidad de Servicio (IPCS)}

El Gobierno de Madrid trabaja para conseguir la participación y colaboración de los empleados públicos en la mejora de la calidad de los servicios que prestamos, con el fin de obtener la satisfacción de los ciudadanos.

El proceso se inicia mediante la participación de los ciudadanos a través de su participación en Grupos de Trabajo o mediante encuestas presenciales o telefónicas. Teniendo en cuenta sus deseos rediseñamos los servicios y simplificamos los procesos. Ofrecemos la información que tenemos y cada vez unos servicios de mayor calidad. Comunicamos las mejoras y volvemos a preguntar al ciudadano.

¿Cómo preguntamos al ciudadano? En la Comunidad de Madrid consideramos a los ciudadanos no como unos meros administrados destinatarios de una serie de servicios, sino como unos auténticos clientes cargados de derechos. Unos clientes que pa- 
gan sus impuestos a cambio de unas prestaciones que desean recibir con una calidad razonable para el coste que sufragan.

En este contexto realizamos una medición periódica del Índice de Percepción de Calidad del Servicio. Analizamos los criterios cuantitativos y cualitativos y la diferencia entre lo que espera el ciudadano y lo que ofrecemos.

Por ejemplo, éstos son los principales factores objetivos deseados por el ciudadano:

Acceso por teléfono, fax, internet y conocimiento del estado de tramitación de los expedientes. Mejora de la señalización, ampliación de horarios y disponibilidad de folletos informativos y formularios.

Por su parte, los factores subjetivos propuestos por el ciudadano son los siguientes:

Explicar la denegación, asesoramiento, mayor rapidez en la atención, personal preparado y reducción de errores.

Del análisis de los resultados de las 900 encuestas realizadas durante noviembre de 1997, en 9 Oficinas de Información y Atención al Ciudadano de la Comunidad de Madrid, hemos preparado la documentación necesaria para rediseñar el proceso de atención al ciudadano contando con la participación de más de 130 funcionarios de primera linea de contacto al ciudadano. Hay que tener en cuenta que más de 10.000 personas contactan con nosotros cada día y son atendidas por las 400 personas que tienen el cometido de atender al ciudadano.

El Decreto 27/1997 establece la necesaria fijación de valores base como patrones de referencia, e indicadores de calidad tales como receptividad, calidad técnica, tiempos, extensión, flexibilidad, ... y el cálculo periódico de un Índice de Percepción de Calidad de los Servicios (IPCS), como reflejo de la opinión que usuarios y ciudadanos tienen sobre los diferentes servicios que ofrece la Comunidad de Madrid.

Este índice se calcula periódicamente y permite analizar la tendencia de las expectativas de nuestros clientes y la diferencia de las mismas con la percepción de calidad que tienen de nuestros servicios. Es importante señalar que esta información se utiliza para establecer prioridades en el desarrollo de los proyectos de mejora de calidad de nuestros servicios.

\subsection{Aprender de nuestros errores: rediseño del proceso de sugerencias y reclamaciones}

Durante los primeros meses de 1996 se desarrolló a través de un Grupo de Mejora un sistema de gestión de sugerencias y reclamaciones que permite que el ciudadano pueda presentar en cualquier formato en cualquiera de las oficinas de atención al ciudadano su reclamación o sugerencia.
A través de la intranet y con la aplicación informática que desarrolló Informática y Comunicaciones de la Comunidad de Madrid (ICM) la reclamación o sugerencia llega a la Oficina de Atención al Ciudadano Central que se pone en contacto telefóniro con el ciudadano y la distribuye a uno de los siete coordinadores que existen (uno por Consejería) para su respuesta.

El sistema facilita una serie de listados cuyos destinatarios, responsables, unidad de calidad y Consejo de Gobierno utilizan para mejorar la gestión.

Gracias al sistema informático de gestión de sugerencias y reclamaciones, el ciudadano puede presentar su reclamación en cualquier Oficina de Atención al Ciudadano. Nosotros nos ponemos en contacto en 48 horas y hemos asumido el compromiso de responder en 15 días, compromiso que estamos cumpliendo en el $85 \%$ del millar de sugerencias y reclamaciones que recibimos cada año.

\subsection{Comprometerse por escrito: las Cartas de Servicios}

Las Cartas de Servicios ofrecen información sobre el servicio y la unidad prestadora, los horarios y la ubicación. También, establecen nuestro compromiso de calidad concreto, a través de objetivos, indicadores de gestión y estándares de calidad.

Cada Carta de Servicios da a conocer a los ciudadanos parte de la información que está disponible en los sistemas corporativos y en Internet (Base de Datos de Atención al Ciudadano/012), las formas de participación en el diseño del servicio (Base de Datos de gestión de sugerencias y reclamaciones) y los compromisos concretos de calidad (Base de Datos de Indicadores de Gestión o Cuadro de Mando Integral). Nuestro objetivo es que cada una de las 80 unidades y 1.500 servicios cuenten con su Carta al finalizar 1998.

El formato de la Carta busca la sencillez y claridad. Sirva como ejemplo el Decálogo de Derechos de los Ciudadanos ante la Administración. En la actualidad más de 300 empleados públicos trabajan en la preparación de 54 Cartas de Servicios de la Red de Bibliotecas, Centros Educativos, Instalaciones Deportivas, Servicios a la Mujer, Servicios a la Juventud, Hospitales, Servicios al Consumidor, ...

\subsection{Ofrecer una mayor transparencia: Ventanilla Única, Proyecto Ceres, teléfono 012, Internet y OAC's}

En la Comunidad de Madrid hemos asumido un compromiso claro de acercamiento de nuestra Administración a los ciudadanos. Por eso estamos trabajando por fomentar la transparencia y la accesibilidad a la información disponible sobre nuestros servicios, prestaciones y procedimientos. 
En la actualidad está disponible toda la información sobre el directorio de servicios, la oferta pública de empleo y los procesos que tienen relación con la creación de empresas.

A través de Informática y Comunicaciones de la Comunidad de Madrid (ICM), hemos diseñado el Sistema de Información de la Comunidad de Madrid que integra una serie de Bases de Datos a cuya información se puede acceder personalmente visitando la Red de Oficinas de Atención al Ciudadano, telefónicamente a través del teléfono 012 o vía Internet (www.Comadrid.es)

La información disponible actualmente incluye:

1. Directorio de la Comunidad de Madrid hasta nivel de Jefe de Servicio.

2. Guía de Servicios que contiene más de un millar de fichas con los principales servicios ofrecidos por la $\mathrm{Co}$ munidad de Madrid.

3. Toda la información sobre la Oferta Pública de Empleo de la C.M. y los principales ayuntamientos de nuestra Región.

4. Todos los procedimientos para la creación de empleo en la denominada Ventanilla Única para la creación de empleo (72 procesos). Está previsto llegar a los principales trámites que se pueden realizar en nuestra Administración (servicios sociales, procedimientos inmediatos, procedimientos internos, ...), dentro del Plan 500.

Con respecto al Proyecto Ventanilla Única, éste se inició en 1996 con los procedimientos relacionados con la creación de empleo y las organizaciones empresariales Jóvenes Empresarios y CEIM.

Durante dos años hemos trabajado con empleados públicos y empresarios en grupos de mejora donde han participado más de un centenar de personas. También estamos participando con la Dirección General de Política de la Pequeña y Mediana Empresa del Ministerio de Economía y Hacienda en la Comisión de Información y Simplificación Administrativa.

Las ventajas del proceso de Ventanilla Única son la garantía de haber simplificado los procesos previamente, automatizado los trámites y normalizado los impresos. Algo que está propiciando una "implantación tranquila y razonable" de las mejoras.

Hoy es posible acceder directamente a través de internet al web de la Comunidad de Madrid y obtener toda la información necesaria para iniciar cualquiera de los 72 procedimientos disponibles, fases y plazos. Incluso es posible obtener en el domicilio el impreso oficial que una vez completado podrá ser entregado en cualquier oficina de atención al público.

La Comunidad de Madrid participa con otras Administraciones y con la Fábrica Nacional de Moneda y Timbre en el Pro- yecto Ceres, que va a permitir la identificación telemática de destinatarios de servicios.

Muy pronto será posible el envio telemático de documentación administrativa, así como la consulta del estado de tramitación de un expediente directamente a través de internet.

Asimismo caminamos hacia un modelo de Red de Oficinas polivalentes donde el ciudadano pueda elegir donde iniciar la mayoría de los procedimientos administrativos por razones de cercanía y comodidad.

Por último y mediante el acuerdo con el Instituto Nacional de la Seguridad Social (INSS) estamos formando a las 400 personas que están en primera línea atendiendo al ciudadano. Una mayor información sobre este punto aparece en el Manual de Acogida y Atención al Ciudadano.

\subsection{Evaluar la Calidad ofrecida: utilización del Modelo Europeo de Excelencia}

En marzo de 1997, el Consejo de Gobierno de la Comunidad de Madrid aprobó un Decreto que regulaba la utilización del Modelo Europeo de Excelencia para evaluar la calidad de los servicios que prestamos.

Realizamos evaluaciones internas periódicas a las principales unidades de nuestro gobierno, teniendo como referente el Modelo Europeo de Excelencia.

Un modelo que nos está permitiendo comparar los resultados obtenidos en una unidad con los correspondientes a otras unidades de nuestro Gobierno o con unidades de otras organizaciones públicas o privadas.

Anualmente, más de un centenar de directivos y mandos intermedios están siendo formados en la aplicación de este Modelo. En la actualidad estamos preparando materiales que adapten a la Comunidad de Madrid el nuevo modelo Europeo de Excelencia a través de un caso práctico.

Para tener documentación real para elaborar los casos prácticos, estamos realizando dos Evaluaciones Internas por evaluadores externos en dos de las unidades que fueron mención especial del premio a la excelencia y calidad, se trata de las Direcciones Generales de Transportes y de Mujer.

\subsection{Extender nuestras mejores prácticas: los Premios a la Excelencia y Calidad de Servicio Público}

En la Comunidad de Madrid también hemos establecido un sistema para conocer las mejores prácticas, reconociendo el trabajo realizado por las diferentes unidades involucradas en proyectos de mejora de la calidad de servicio. 
Son los Premios Anuales a la Excelencia y Calidad de Servicio. Unos premios que van dirigidos a prestadores directos tales como hospitales, residencias de personas mayores, bibliotecas, instalaciones deportivas, ...

Este año a la primera convocatoria se presentaron 26 iniciativas de diferentes unidades, que representaban el trabajo de 3.000 empleados públicos, resultando ganadora el Centro Tecnológico de Madrid, CETEMA, una empresa pública regional dedicada a mejorar el tejido empresarial de la Comunidad de Madrid por su Plan de Calidad que sigue el Modelo Europeo de Excelencia.

El Jurado presidido por el Presidente de la Comunidad de Madrid y compuesto por cinco personas, tres de ellas especialistas (externos) en realizar evaluaciones de acuerdo con el Modelo Europeo de Excelencia.

Este Jurado en 1998 acordó tambien conceder cuatro menciones especiales:

- a la Universidad Carlos III,

- al Servicio de Emergencia y Rescate (SERCAM),

- a la unidad de atención al ciudadano de transportes

- y al servicio de atención social a la mujer.

En esas iniciativas y las presentadas por los 8 finalistas se podía ver el compromiso entre la dirección y los trabajadores con la mejora continua, así como la preocupación por ofrecer unos servicios de calidad de acuerdo a las expectativas de sus clientes.

Hemos preparado una Memoria completa de las iniciativas presentadas al premio y, en la actualidad, estamos trabajando en la elaboración de una Memoria de las Mejores Prácticas donde recojamos, para nuestros directivos y especialistas, las principales actividades de calidad realizadas en la Comunidad de Madrid, siempre teniendo como referencia los criterios del Modelo Europeo de Excelencia.

Nuestro objetivo final es hacer competir a las diferentes unidades de nuestra Administración en Excelencia y Calidad, fomentar y apoyar las iniciativas de mejora que por parte de las distintas unidades prestadoras de servicios al ciudadano se realicen.

Los aspectos más valorados por el Jurado, compuesto mayoritariamente por miembros ajenos a la Comunidad de Madrid, fueron los resultados de la opinión de los ciudadanos y que las mejoras implantadas hubieran partido del acuerdo entre directivos y empleados.

Por otra parte, hay que destacar que el premio toma como referencia el modelo de Calidad Total de la Fundación Europea para la Gestión de la Calidad (EOQ-EFQM), que viene aplicando la Dirección General de Calidad de los Servicios en la realización de las evaluaciones intemas a las distintas unidades que componen la Administración regional madrileña descle enero de 1996.
Es por ello que el premio tiene un doble carácter, no sólo recompensar la mejora efectiva y comprobada en la prestación de los servicios al ciudadano por parte de las distintas unidades que componen la Administración de la Comunidad de Madrid, sino además fomentar la implantación de proyectos de mejora cuyo beneficiario sea el ciudadano de la Comunidad de Madrid, considerado como un cliente de la misma y fin último de su actividad.

Se han establecido dos fases para la concesión del premio: una primera de preselección de unidades candidatas, realizada por los técnicos de la Dirección General de Calidad de los Servicios, y una segunda de valoración de las candidaturas preseleccionadas y de concesión del premio, que es realizada por un Jurado.

Las unidades ganadoras del premio tienen derecho a usar el logotipo del mismo durante tres años. Después de este plazo necesitarán volver a presentarse y obtenerlo para poder seguir usándolo.

Con el distintivo del premio pretendemos difundir entre nuestros clientes una marca de calidad que implique la existencia de un sistema propio de certificación de la calidad de los servicios que prestamos al ciudadano.

Mediante la introducción de un sistema de reconocimiento público de las mejores unidades y de las mejores iniciativas de calidad, pretendemos además aprender de los mejores.

Sabemos que en nuestra organización hay directivos y trabajadores firmemente comprometidos en gestionar y controlar los resultados teniendo como referente prioritario las demandas de los ciudadanos que se transforman en clientes.

\subsection{Transmitir el conocimiento: la gestión del conocimiento y la formación como elementos clave}

Durante los primeros meses de su funcionamiento, los integrantes de la Dirección General de Calidad de los Servicios compatibilizaron la realización de proyectos de mejora en diferentes áreas con una formación especifica intensiva en técnicas y herramientas de calidad, mediante el desarrollo de un programa de más de 120 horas.

La experiencia adquirida por nuestros consultores e inspectores durante estos últimos años en la implantación de diferentes proyectos piloto permitió la puesta en marcha a mediados de 1997 del curso aModelo Europeo de Excelencia y Herramientas de Calidad, un curso en el que durante 20 horas se "entrena" a empleados públicos de nuestra Administración en el manejo del Modelo y de las principales herramientas de gestión que han sido adaptadas al entorno de la Comunidad de Madrid.

Cada año más de un centenar de Jefes de Servicio, Jefes de Sección y Técnicos de las 7 Consejerías tienen la oportunidad 
de participar en una actividad formativa absolutamente práctica, que es impartida por unos especialistas que además son funcionarios de la Comunidad de Madrid.

Sin embargo, pese a haber logrado extender el conocimiento sobre el Modelo Europeo de Excelencia y sobre las principales herramientas de calidad dentro de nuestra organización, somos conscientes de que era preciso la recopilación en una publicación de los principales materiales de trabajo para permitir su acceso directo a aquellos que quieran tener un mayor conocimiento de estas materias.

Cuando se busca el objetivo de extender los conocimientos de calidad que poseemos en una organización que actualmente cuenta con más de 35.000 integrantes y que con las transferencias de educación y sanidad sobrepasará los 100.000 empleados públicos, es imprescindible realizar publicaciones específicas que permitan ese objetivo con éxito.

Sin embargo, somos conscientes de que el futuro de la transmisión del conocimiento en nuestra organización va más allá de pilotar el plan de formación en calidad y de preparar publicaciones específicas.

Hay determinadas cuestiones que nos planteamos si consideramos a la Comunidad de Madrid como una organización prestadora de servicios públicos al ciudadano, repleta de conocimiento y de capital intelectual. Por ejemplo:

¿Cuáles son nuestras mejores prácticas? ¿Cómo podré enseñar a mi organización a mejorar? ¿Qué hicimos hace dos años con un problema similar al nuestro? ¿Cómo puedo mejorar el proceso preguntando a quienes ya lo conocen?

Para dar respuesta a estas preguntas y a otras del mismo tipo, estamos trabajando con los conceptos de capital intelectual y gestión del conocimiento en la Comunidad de Madrid. Nuestro objetivo es utilizar la experiencia piloto concreta desarrollada en la Dirección General de Calidad de los Servicios, donde se han agrupado conocimientos, se han adaptado a diferentes entornos y se han sabido transmitir y reutilizar en diferentes ámbitos.

En una organización como la nuestra, prestadora de más de 1.500 servicios distintos a más de 5 millones de clientes, es indispensable aprovechar los conocimientos comunes en diferentes áreas de gestión. Unas áreas que tienen muchos puntos en común lo que hace idónea la implantación de sistemas que permitan compartir los conocimientos.

Si analizamos uno solo de los "núcleos" del modelo de gestión del conocimiento aplicado a la Comunidad de Madrid, por ejemplo el núcleo "calidad" que agrupa los principales conocimientos sobre gestión de calidad, modelo europeo de excelencia, rediseño de procesos,...vemos que hay una vía de entrada "incorporar" y una vía de salida "reutilizar", así como tres proce- sos internos que con los anteriores forman un ciclo, compartir, generar y adaptar.

Veamos a continuación un desarrollo y contenido práctico de los conceptos apuntados:

\section{Compartir conocimiento}

Compartir experiencias en el ámbito de la calidad, técnicas y soluciones. Enseñar y aprender. Permitir aprender. Potenciar el intercambio de conocimientos. Fomentar la formación interna mediante sesiones de trabajo.

\section{Incorporar conocimiento}

Saber buscar el conocimiento que se necesita. Saber navegar por las redes de información externas e internas. Se logra potenciando el Benchmarking y la realización de sesiones de intercambio con otras organizaciones. Incorporación de conocimientos vía expertos o bibliografía. Es importante aplicar un código ético que evite malentendidos con otras organizaciones. Por ejemplo, la firma de un convenio de colaboración con otra organización pública (Convenio INSS-Comunidad de Madrid para la formación del personal de primera línea de contacto con los ciudadanos).

\section{Generar conocimiento}

Generar el conocimiento que no se posea y se necesita para mejorar la gestión. Potenciar a las personas para que sean capaces de crear, fomentando la creatividad. Aplicación de técnicas de creatividad y nombramiento de "expertos temáticos" que puedan reflexionar libremente en su ámbito. Ésta es quizás la tarea más compleja y viene determinada por la capacidad técnica del personal y del ambiente de trabajo. Es la función típica de I+D.

\section{Adaptar el conocimiento}

Formatear el conocimiento para poder transferir a otras personas y áreas. Se trata de adaptar técnicas, herramientas y metodologías al entorno propio. Por ejemplo, la adaptación de una metodología de rediseño de procesos al entorno administrativo de la Comunidad de Madrid o la realización de grupos de mejora.

\section{Reutilizar el conocimiento}

Reutilizar el conocimiento en otras áreas para solucionar problemas similares en otros entornos. "Cesión" a otras personas 
y organizaciones de nuestro conocimiento en las áreas donde se es Best practice.

El proceso de gestión del conocimiento pretende una serie de objetivos entre los cuales cabe destacar:

- Dar un mayor valor a las personas vs valor de los puestos que éstas ocupan.

- Incrementar la madurez de la organización desarrollándo las personas.

- Posibilitar el reconocimiento público incrementando la transparencia interna.

- Compartir el liderazgo y el éxito.

- Incrementar la polivalencia de los puestos y la motivación de sus integrantes.

- Fomentar el trabajo en equipo fomentando el aprendizaje mutuo.

- Conseguir la identificación de las personas con los objetivos corporativos.

- Terminar con el anonimato de las personas mediante la participación.

El reto de la calidad nos obliga a estar inmersos en un proceso de mejora continua y es precisamente la gestión del conocimiento una herramienta eficaz para aprovechar el saber hacer de las mejores prácticas.

En la Comunidad de Madrid ya hemos iniciado esta vía a través de los premios a la excelencia y calidad que nos permiten hacer aflorar los mejores proyectos, paso previo a incorporar a las personas al programa formativo como profesores y las prácticas a las publicaciones y a la intranet puesta en marcha por Informática y Comunicaciones de la Comunidad de Madrid (ICM) operativa desde comienzos de 1998.

Espero que seamos capaces de gestionar nuestro gran conocimiento siempre teniendo como referente las demandas de los ciudadanos, cuya satisfacción es nuestra principal razón de ser como Comunidad de Madrid.

\section{Anexo}

- Direcciones de contacto.

- Principales publicaciones de la unidad.

- Decálogo de Derechos de los Ciudadanos.

- Decretos 27/1997 y 44/1998 reguladores del sistema de calidad de los sérviciós püblicos en la C.M.
- Orden 1417/1998 de convocatoria del II Premio Anual a la Excelencia y Calidad de los Servicios.

\section{Direcciones de contacto:}

La Dirección General de Calidad de los Servicios mantiene fluidas relaciones con aquellas organizaciones públicas que comparten el objetivo de mejora continua en la prestación de servicios al ciudadano.

Mayor información:

Consejería de Hacienda de la Comunidad de Madrid

Plaza de Chamberí 8 -28010 Madrid

Fax: 5803403

En internet: www.comadrid.es

E-Mail: dg.calidad @ comadrid.es

\section{Principales publicaciones de la unidad}

En la página web de la unidad está disponible toda la normativa que regula el Plan de Calidad de la Comunidad de Madrid, servicios prestados por la unidad, así como un resumen de las principales metodologías utilizadas. Además, la Dirección General de Calidad de los Servicios ha editado las siguientes publicaciones:

1. Guía para el rediseño de procedimientos administrativos de la Comunidad de Madrid (con asesoramiento de Coopers \& Lybrand).

2. Guía para la implantación de la Ventanilla Única en la Comunidad de Madrid (con asesoramiento de KPMG Peat Marwick).

3. Manual de Acogida y atención al Ciudadano de la Comunidad de Madrid (con asesoramiento de Coopers \& Lybrand Gálgano).

4. Guía para la Gestión, el Control y el Seguimiento de Subvenciones de la Comunidad de Madrid (con asesoramiento de KPMG Peat Marwick).

5. Excelencia y Calidad en los Servicios Públicos. 1997-1998. Memoria del Plan de Calidad y del Premio.

\section{En preparación:}

6. Manual del Directivo Público de la Comunidad de Madrid (con asesoría de Arthur Andersen).

7. Implantación del Plan de Calidad en la Comunidad de Madrid. 
8. Adaptación del Modelo Europeo de Excelencia a la Comunidad de Madrid (con asesoramiento de Price Waterhouse).

9. Memoria de la Mejores Prácticas en la Comunidad de Madrid según los criterios del Modelo Europeo de Excelencia (con asesoramiento de Price Waterhouse).

\begin{tabular}{|c|}
\hline 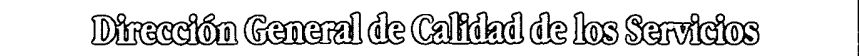 \\
\hline $\begin{array}{l}\text { Declaración del Presidente de la Comunidad de Madrid en la } \\
\text { III Semana Europea de Calidad }\end{array}$ \\
\hline Presentación de Calidad de los Servicios. \\
\hline Guía para el diseño de procedimientos administrativos de la Comunidad de Madrid. \\
\hline El desarrollo del Plan de Calidad de la Comunidad de Madrid. \\
\hline $\begin{array}{l}\text { Decreto 27/1997, de } 6 \text { de marzo, por el que se regulan las Cartas de Senricios, los } \\
\text { Sistemas de Evaluación de la Calidad y los Premios Anuales a la Excelencia y Ca- } \\
\text { lidad del Servicio Público en la Comunidad de Madrid. }\end{array}$ \\
\hline $\begin{array}{l}\text { Decreto 44/1998, de } 18 \text { de marzo, por el que se aprueban medidas complementarias } \\
\text { de regulación de las Cartas de Senvicios. }\end{array}$ \\
\hline $\begin{array}{l}\text { Orden 1417/1998, de } 5 \text { de junio, de la Consejería de Hacienda, por la que se } \\
\text { convoca el II Premio Anual a la Excelencia y Calidad del servicio público en la } \\
\text { Comunidad de Madrid. }\end{array}$ \\
\hline $\begin{array}{l}\text { Orden 2381/1997, de } 20 \text { de octubre, de la Consejería de Hacienda, por la que se } \\
\text { regulan los sistemas de identificación del personal al servicio de la Comunidad de } \\
\text { Madrid y de señalización de sus edificios y oficinas administrativas. }\end{array}$ \\
\hline $\begin{array}{l}\text { Orden } 819 / 1997 \text {, de } 21 \text { de abril, de la Consejería de Hacienda, sobre inclusión en } \\
\text { los trabajos de imprenta, do información relativa al número de ejemplares de la } \\
\text { tirada, coste unitario y nümero y fecha de la edición. }\end{array}$ \\
\hline $\begin{array}{l}\text { Excelencia y Calidad en los Servicios Públicos. Plan de Calidad y Memorias del } \\
\text { Premio 1997-1998. }\end{array}$ \\
\hline
\end{tabular}

Dirección General de Calidad de los Servicios. Consejería de Hacienda. Comunidad de Madrid. Plaza de Chamberí, 8 - 28010 Madrid. Teléfono: + 34-1-580.33.53. Fax: + 34-1-580.34.03.

\section{El desarrollo del Plan de Calidad de la Comunidad de Madrid}

\section{La Dirección General de Calidad de los Servicios}

Esta unidad dependiente del Consejero de Hacienda, creada en julio de 1995, tiene como misión apoyar al resto de unidades del Gobierno Regional en la mejora de la calidad de los servicios públicos. El Decreto 113/1997 estableció su estructura y competencias.
Éste es el enunciado de las mismas:

- Formulación de normas e instrucciones de carácter general y el establecimiento de criterios y directrices en materia de organización administrativa enfocados a la racionalización de los procedimientos administrativos y a la mejora de los métodos de gestión administrativa.

- Elaboración de informes y el establecimiento de directrices generales en procesos operativos, métodos de gestión administrativa, seguimiento de objetivos y dimensionado de plantillas, acercando los puntos y simplificando las formas de atención al ciudadano.

- Formulación, aplicación y seguimiento de planes de calidad en el proceso de gestión de prestación de servicios, así como el control del nivel de satisfacción que el ciudadano mantiene de los mismos.

- Evaluación del ajuste de la gestión pública autonómica a las demandas de los ciudadanos y a los estándares de calidad fijados en colaboración con las diferentes unidades responsables de los servicios públicos de la Comunidad de Madrid, impulsando y asesorando a las mismas en la elaboración de las correspondientes Cartas de Servicios.

- Medición periódica del indice de percepción de calidad del servicio al que hace referencia el Decreto 27/1997, de 6 de marzo.

- Realización periódica de evaluaciones internas sobre la base de los criterios definidos en el Modelo Europeo de Excelencia (EFQM-EOQ).

- Impulso de la introducción de técnicas de gestión y evaluación que permitan mejorar las prestaciones de los servicios y la simplificación de los trámites administrativos realizados en el seno de la Comunidad de Madrid.

- Planificación y coordinación de la implantación de un Plan de Calidad en la Administración Regional.

Para cumplir dichos objetivos, esta unidad se ha estructurado en los siguientes Servicios:

- Servicio de Inspección.

- Servicio de Evaluación Interna.

- Servicio de Seguimiento de la Calidad.

- Servicio de Consultoría de Gestión.

Estos servicios desarrollan los trabajos y proyectos realizados por los coordinadores de proyectos, inspectores, consultores de organización y técnicos de organización que componen la unidad. 


\section{Normativa especifica}

Para lograr una mayor eficacia en la implantación del Plan de Calidad en nuestra organización, la Comunidad de Madrid se ha dotado de un marco normativo específico.

En concreto, el Consejo de Gobierno ha aprobado durante el año 1997, dos Decretos, el 27/1997 y el 113/1997. El primero de ellos regula las Cartas de Servicios, los sistemas de evaluación de la calidad y los premios anuales a la excelencia y calidad del servicio público en la Comunidad de Madrid.

El segundo establece las competencias y estructura de la Dirección General de Calidad de los Servicios.

Por su parte, el Consejero de Hacienda en este período ha dictado las Órdenes 819/1997 y 2381/1997, regulando tanto la realización de trabajos de imprenta de acuerdo con las directrices del Plan de Ahorro, como la identificación del personal de atención al ciudadano en su relación con ella.

A continuación, se presenta un breve resumen práctico del contenido de la normativa citada con el objeto de servir de guía tanto para los responsables de la Comunidad de Madrid, encargados de su implantación, como para general conocimiento de los ciudadanos.

\section{Evaluaciones internas}

La Comunidad de Madrid, para la realización de evaluaciones internas de calidad de sus unidades y servicios, ha optado por aplicar el Modelo Europeo de Excelencia definido por la European Foundation for Quality Management y la European Organization for Quality (EFQM-EOQ).

El Modelo, que ha sido adaptado a la Comunidad de Madrid, se estructura en nueve criterios: cinco referidos a los Agentes (Liderazgo, Estrategia, Gestión del Personal, Recursos y Procesos) y cuatro referidos a los Resultados (Satisfacción del Cliente, Satisfacción del Personal, Impacto en la Sociedad y Resultados). Cada elemento, a su vez, se desagrega en varios subcriterios.

El uso del Modelo Europeo de Excelencia en la Comunidad de Madrid ha implicado la formación de directivos y mandos intermedios para posibilitar su aplicación como modelo de referencia en las autoevaluaciones realizadas en nuestros servicios.

La utilización de este Modelo en las evaluaciones internas permite comparar los resultados obtenidos en una determinada unidad con los correspondientes a otras unidades de la Comunidad de Madrid, o de otras organizaciones públicas o privadas. Con estas evaluaciones se busca valorar la habilidad de una unidad para mejorar su gestión de forma continuada, mediante la adopción del objetivo de trabajar por implantar la Calidad Total en la organización.

\section{La voz del cliente}

\section{Indice de Percepción de Calidad del Servicio (IPCS)}

En el seno de la Comunidad de Madrid se presta una especial atención a la Voz del Cliente, ya sea a través de la medición periódica del Índice de Percepción de la Calidad del Servicio, o mediante el análisis de las sugerencias y reclamaciones presentadas por los ciudadanos en su relación con los servicios que presta la Comunidad de Madrid.

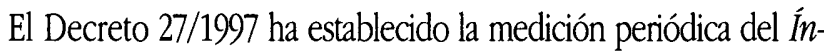
dice de Percepción de Calidad del Servicio, el cual proporciona el conocimiento del grado de satisfacción de los usuarios y ciudadanos en relación con los servicios que presta nuestra organizacion.

Este índice permite conocer en qué medida los ciudadanos están satisfechos con los aspectos concretos de la prestación del servicio y cuál es la prioridad que otorgan a cada uno de los factores. Analizamos los criterios cuantitativos y cualitativos (ya sean estos últimos objetivos o subjetivos) y la diferencia entre lo que espera el ciudadano y lo que le ofrecemos, estableciendo las prioridades en el desarrollo de los proyectos de mejora de la calidad de nuestros servicios.

\begin{tabular}{|c|c|c|c|}
\hline \multicolumn{4}{|c|}{ 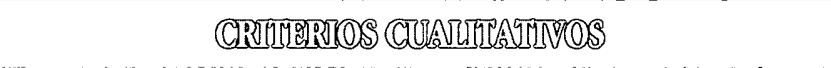 } \\
\hline \multirow{3}{*}{ 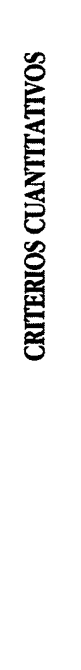 } & & Factores objetivos & Factores subjetivos \\
\hline & 㐫 & $\begin{array}{l}\text { 1. Acceso (tfno., fax, ...). } \\
\text { 2. Conocer estado tramitación. } \\
\text { 5. Buena señalización. } \\
\text { 6. Horario amplio. } \\
\text { 8. Folletos y formularios. }\end{array}$ & $\begin{array}{l}\text { 3. Explicar denegación. } \\
\text { 4. Asesoramiento. } \\
\text { 7. Rapidez en la atención. } \\
\text { 9. Personal preparado. } \\
\text { 10. No cometer errores. }\end{array}$ \\
\hline & & $\begin{array}{l}\text { 16. Buena comunicación. } \\
\text { 13. Instalaciones. } \\
\text { 18. Condiciones ambientales. }\end{array}$ & $\begin{array}{l}\text { 11. Lenguaje claro. } \\
\text { 12. Entender necesidades. } \\
\text { 14. Amabilidad. } \\
\text { 15. Intimidad/confidencialidad. } \\
\text { 17. Sin internınrinnes }\end{array}$ \\
\hline
\end{tabular}

\section{Su opinión nos ayuda a mejorar}

A través del Sistema de Sugerencias y Reclamaciones del ciudadano ante la Comunidad de Madrid es posible canalizar toda esta información para mejorar la calidad de nuestros servicios. 
En la actualidad el ciudadano puede presentar en las principales Oficinas de Atención al Ciudadano sus sugerencias y reclamaciones en cualquier formato. Nos ponemos en contacto con el ciudadano en un plazo inferior a 48 boras y nuiestro compiomiso es responder en menos de 15 días.

El tratamiento informático de las sugerencias y reclamaciones nos permite realizar un análisis detallado de sus causas, trabajando con los responsables de los servicios en la mejora continua de los mismos.

\section{Cartas de Servicios y Premios a la Excelencia y Calidad}

\section{Nuestros compromisos de Calidad}

Tras la publicación en 1996 del Decálogo de Derechos de los Ciudadanos, el Consejo de Gobierno de la Comunidad de Madrid aprobó el 6 de marzo de 1997 el Decreto 27/1997, que regula las Cartas de Servicios, los sistemas de evaluación de la calidad y los premios anuales a la excelencia y calidad del servicio público en la Comunidad de Madrid.

Las Cartas de Servicios son documentos que informan al ciudadano sobre las condiciones en que se prestan los servicios públicos por parte de la Comunidad de Madrid, describiendo la unidad y haciendo públicos nuestros compromisos de calidad.

\begin{tabular}{|c|c|c|c|}
\hline \multicolumn{4}{|c|}{ 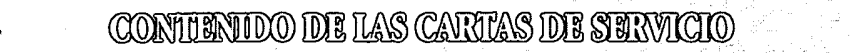 } \\
\hline \multirow{4}{*}{ 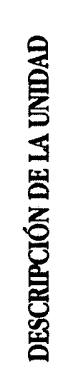 } & $\begin{array}{l}\text { Los objetivos y modalidades de } \\
\text { participación de los ciudadanos. }\end{array}$ & \multirow{4}{*}{ 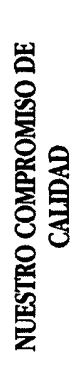 } & $\begin{array}{l}\text { Acceso al sistema de } \\
\text { Reclamaciones y Sugerencias. }\end{array}$ \\
\hline & $\begin{array}{l}\text { Relación de servicios y breve } \\
\text { definición de los mismos. }\end{array}$ & & Descripción de los objetivos. \\
\hline & $\begin{array}{l}\text { Descripción de los servicios } \\
\text { ofrecidos. }\end{array}$ & & $\begin{array}{l}\text { Fijación de estándares de } \\
\text { calidad. }\end{array}$ \\
\hline & $\begin{array}{l}\text { Ubicación de las dependencias } \\
\text { y horario. }\end{array}$ & & Criterios de actualización. \\
\hline
\end{tabular}

Nuestras mejores prácticas

Los Premios a la Excelencia y Calidad fueron creados por el Decreto 27/1997 y son convocados anualmente por Orden del Consejero de Hacienda.

Obtener el premio supone un reconocimiento público a la excelencia en los servicios prestados por una unidad eficaz, que sus servicios son los mejores y que su organización está concienciada y es responsable respecto a los ciudadanos que utilizan dichos servicios.
Los destinatarios del premio son aquellas unidades de la Administración de la Comunidad de Madrid que se hayan distinguido en la realización de actividades de mejora en la calidad del servicio ofrecido al ciudadaño, y está peñsado para unidades tales como oficinas de atención al ciudadano, hospitales, residencias de personas mayores, albergues juveniles, escuelas, universidades, bibliotecas, instalaciones deportivas, centros de atención al menor, y cualquier unidad con rango mínimo de servicio.

Del análisis de las candidaturas y de los premiados publicamos anualmente la Memoria de Mejores Prácticas de la Comunidad de Madrid para uso de directivos y especialistas.

\section{Información de calidad para el ciudadano de Madrid}

\section{El Sistema de Información}

En la Comunidad de Madrid hemos asumido un claro compromiso por acercar la Administración a los ciudadanos. Una de las vías principales para lograr este objetivo es fomentar la transparencia y la accesibilidad a la información disponible sobre nuestros servicios, prestaciones y procedimientos. Para ello, a través de Informática y Comunicaciones de la Comunidad de Madrid (ICM), hemos diseñado el Sistema de Información de la Comunidad de Madrid, que integra una serie de Bases de Datos a cuya información se puede acceder personalmente visitando la Red de Oficinas de Atención al Ciudadano, telefónicamente a través del teléfono 012 o vía Internet.

Entre las Bases de Datos disponibles destaca la Base de Datos de Servicios, que ofrece una información general sobre todos los servicios y prestaciones que proporciona la Comunidad de Madrid a los ciudadanos. Respecto a cada servicio ofrecemos la siguiente información:

- Breve descripción del contenido del servicio.

- Prestaciones y población a la que se dirige.

- Requisitos y documentación necesaria para acceder al mismo.

- Unidad responsable, denominación y teléfono de contacto.

- Normativa de apoyo.

\section{Ventanilla Única de la Comunidad de Madrid}

En 1996 la Comunidad de Madrid inició el Proyecto de Ventanilla Única comenzando por los procesos relacionados con la creación de empleo. Este proyecto está sirviendo para mejorar la eficacia en la tramitación de los procedimientos y la accesibilidad de los ciudadanos a la información. 
Hoy la Ventanilla Única de la Comunidad de Madrid ofrece, a través de una Base de Datos específica integrada en el Sistema de Información al Ciudadano:

- Información detallada sobre los procedimientos incluidos hasta el momento (requisitos y trámites esenciales, documentación necesaria, plazos, legislación y organismo responsable).

- Los impresos oficiales para iniciar los procedimientos.

Seguimos trabajando en la inclusión de los 500 principales procedimientos en la Ventanilla Única a través del Plan 500 y en ofrecer además las siguientes prestaciones:

- Seguimiento del estado de tramitación de los expedientes.

- Identificación de la persona responsable de su tramitación.

- Gestión de los Procedimientos Directos en menos de 30 minutos y desde varias oficinas.

El acceso a la Ventanilla Única puede realizarse desde las principales Oficinas de Atención al Ciudadano, a través del teléfono 012 o Internet.

\section{Decreto 27/1997, de 6 de marzo, por el que se regulan las Cartas de Servicios, los Sistemas de Evaluación de la Calidad y los Premios Anuales a la Excelencia y Calidad del Servicio Público en la Comunidad de Madrid.}

\section{PREÁMBULO}

Nuestro ordenamiento jurídico-constitucional prevé como finalidad de la Administración Pública la de servir a los intereses generales de la sociedad, actuando para ello de acuerdo con unos principios propios de un Estado social y democrático de Derecho. En las últimas décadas, el Estado se ha erigido en uno de los principales suministradores de bienes y servicios al conjunto de los ciudadanos, por lo que su actividad constituye un elemento decisivo en el establecimiento de las condiciones necesarias para el incremento de la calidad y la competitividad nacional.

La reforma y modernización de la Administración Pública y, en concreto, de la Administración de la Comunidad de Madrid, constituye un proceso dinámico y de continua adaptación, en sus formas organizativas y funcionales, a las transformaciones sociales, económicas y tecnológicas de su entorno. En este sentido, nuestra Administración no puede permanecer ajena a la introducción en sus organizaciones de la cultura y las técnicas de gestión de la calidad, responsabilizándose, así, de la calidad global de los servicios, cuyos costes directos y los derivados de la ausencia de calidad en su prestación repercuten sobre los ciudadanos, en tanto que destinatarios y sostenedores de los mismos a través de los tributos.

Cada ciudadano tiene derecho a conocer cómo se utilizan los recursos a los que contribuye, debiendo responder nuestra Administración con un esfuerzo informativo y un ejercicio de transparencia para que conozca cabalmente cuáles son las prestaciones que puede demandar, así como en qué términos, con qué requisitos, con qué extensión y en qué condiciones o formas se le ofrecen.

Este Decreto persigue, por tanto, un doble objetivo. Por una parte, instrumentar la declaración concreta de la misión propia de nuestra Administración y, por otra, facilitar el conocimiento por los ciudadanos de lo que pueden esperar de aquélla. Tal es la finalidad de las Cartas de Servicios, que se articulan como documentos accesibles al público en general, a través de los cuales los órganos de la Administración Autonómica y sus entidades difunden los compromisos de calidad de sus servicios frente al ciudadano.

Las Cartas de Servicios constituyen, así, instrumentos idóneos para actualizar el ejercicio de los derechos de los ciudadanos al proporcionarles una influencia más directa sobre los propios servicios públicos, para fomentar la mejora.continua de su calidad y para hacer explícita la responsabilización dẹ los gestores públicos ante los ciudadanos, a los que transforman en verdaderos clientes de la Administración.

La heterogeneidad de los servicios y prestaciones dispensados por los diversos órganos y entidades de la Administración Autonómica desaconseja el establecimiento de un modelo uniforme y cerrado de Carta de Servicios. Antes bien, es preciso determinar los aspectos clave que, en cualquier caso, deben tratar, permitiendo la plasmación concreta de los correspondientes compromisos y niveles o estándares en cada Carta singular. Asimismo, se conciben las cartas como documentos revisables que, mediante la actualización periódica de los compromisos, deben reflejar permanentemente las mejoras del servicio y adaptarse a las nuevas expectativas de los usuarios.

Toda iniciativa general de mejora de la calidad en las organizaciones públicas precisa obviamente del establecimiento de sistemas de evaluación que permitan apreciar el grado de consecución de los objetivos fijados y el impacto de los resultados realmente obtenidos. Para ello, este Decreto dispone la implantación de un sistema de evaluación estructurado en dos planos: la autoevaluación de cada uno de los órganos o entidades de acuerdo con unos criterios determinados y la evaluación global e integrada del conjunto de los servicios públicos, con lo que nuestra región se suma a las recomendaciones de la Organización para la Cooperación y el Desarrollo Económico (OCDE) acerca de la necesidad de establecer sistemas de medición del 
rendimiento y calidad de la Administración Pública como medio imprescindible para mejorar su utilidad social.

Por último, en línea con las medidas anteriores y, tomando como marco de referencia iniciativas de otras Administraciones Públicas, se crea a través del presente Decreto el Premio anual a la excelencia y calidad del servicio público en la Comunidad de Madrid, a fin de reconocer el esfuerzo que las unidades administrativas realicen en la consecución de la mejora de la calidad de los servicios que presten a los ciudadanos.

En su virtud, a propuesta del Consejero de Hacienda, y previa deliberación del Consejo de Gobierno de la Comunidad de Madrid en su reunión del día 6 de Marzo de 1997,

\section{DISPONGO}

\section{CAPÍTULO I}

\section{Disposiciones Generales}

Artículo 1. Objeto.

El presente Decreto tiene por objeto regular las Cartas de Servicios, los sistemas de evaluación de la calidad, así como los premios anuales a la excelencia y calidad del servicio público en la Comunidad de Madrid.

\section{Artículo 2. Ámbito de aplicación.}

El presente Decreto será de aplicación a los órganos de la Administración de la Comunidad de Madrid, así como a los organismos autónomos y demás entidades de Derecho público de la misma, cuando gestionen prestaciones o servicios directos a los ciudadanos.

Sin perjuicio de lo anterior, las empresas públicas con forma de sociedad mercantil, que presten servicios directos a los ciudadanos, podrán acogerse a las medidas previstas en esta disposición, cuando así lo decidan sus órganos de gobierno y dirección.

\section{CAPÍTULO II}

\section{Las Cartas de Servicios}

\section{Artículo 3. Definición y contenido.}

Las Cartas de Servicios son documentos que tienen por objeto informar al ciudadano acerca de las cualidades con que se proveen las prestaciones y servicios públicos. Habrán de expresar: a) La naturaleza, contenido, características y formas de proveer las prestaciones y servicios.

b) La determinación de los niveles o estándares de calidad en la provisión del servicio.

c) Los mecanismos de consulta a los usuarios acerca de los servicios que aquéllos demanden y de sus sugerencias y opiniones para la mejora de los mismos.

d) El sistema de evaluación de la calidad.

\section{Artículo 4. Prescripciones de contenido.}

Las Cartas de Servicios se redactarán en términos claros y fácilmente comprensibles para los ciudadanos y se estructurarán en los siguientes apartados:

1. De carácter general y legal.

a) Identificación del órgano en entidad prestador del servicio y de su Consejería de adscripción.

b) Descripción genérica de los fines del órgano o entidad.

c) Catálogo de las prestaciones o servicios dispensados con una descripción concisa e inteligible de todas su modalidades.

d) Articulación de las modalidades de participación de los ciudadanos y usuarios.

e) Relación, periódicamente puesta al día, de las referencias normativas de cada una de las prestaciones y servicios.

f) Disponibilidad y acceso al "Sistema de Reclamaciones y Sugerencias ante la Comunidad de Madrid" sobre el funcionamiento de los servicios.

2. De compromisos de calidad.

a) Determinación explícita de los niveles o estándares de calidad ofrecida, en aspectos como:

- Plazos previstos de tramitación.

- Mecanismos de comunicación e información, ya sea general o personalizada.

- Horario de atención al público.

- Cualesquiera otros que, adecuados a las peculiaridades de cada prestación o servicio, se consideren relevantes y se esté en condiciones de facilitar a los ciudadanos.

b) Especificación de los criterios para la actualización de los compromisos declarados. 
3. De carácter complementario.

a) Directorio de oficinas donde se presta cada uno de los servicios. Si.se dispone de una red descentralizada se relacionarán las direcciones de todas ellas.

b) Identificación y dirección de la unidad responsable de la Carta.

c) Referencia de otras informaciones divulgativas sobre los servicios gestionados.

\section{Artículo 5. Elaboración y gestión de las Cartas de Servicios.}

Los titulares de los órganos y entidades a que se refiere el artículo 2 de este Decreto designarán la unidad administrativa, con rango mínimo de Jefatura de Servicio, responsable de la elaboración y gestión de la correspondiente Carta de Servicios y de los sistemas de autoevaluación de la calidad previstos en el artículo 9 de esta disposición.

Artículo 6. Aprobación y difusión.

1. Las Cartas de Servicios serán aprobadas por resolución del titular del órgano o del máximo responsable de la entidad a cuyos servicios se refieren aquéllas. La resolución se publicará en el "Boletín Oficial de la Comunidad de Madrid", anunciando la existencia y disponibilidad de dicha Carta.

2. Cada órgano o entidad llevará a cabo las acciones divulgativas de su Carta de Servicios que estime más eficaces, siempre que se garantice su accesibilidad para los usuarios en todas las dependencias administrativas con atención al público.

3. Una vez aprobada la Carta, se remitirá un ejemplar completo a la Dirección General de Calidad de los Servicios para su registro y debida constancia. No obstante, con carácter previo, podrá recabarse el apoyo y asesoramiento de dicha unidad para la elaboración de la Carta.

\section{CAPÍTULO III.}

\section{Evaluación de la calidad de los servicios públicos}

\section{Artículo 7. Finalidad.}

1. La evaluación de la calidad de los servicios públicos tiene el doble objeto de, por una parte, proporcionar al Gobierno de la Comunidad de Madrid la información agregada necesaria para planificar y dirigir la acción administrativa de servicio a los ciudadanos así como para adoptar las iniciativas de mejora requeridas $y$, por otra, hacer llegar a los ciudadanos la informa- ción precisa sobre los niveles de calidad realmente prestados para facilitarles el ejercicio efectivo de sus derechos ante la Administración.

2. A estos efectos, la evaluación de la calidad constituye un proceso integral que engloba el diagnóstico sobre los niveles efectivos de prestación de los servicios y su relación con las expectativas de los ciudadanos, así como la medición del grado de cumplimiento de los compromisos declarados.

\section{Artículo 8. Sistemas de evaluación de la calidad.}

Para alcanzar los fines descritos en el artículo anterior, la evaluación de la calidad de los servicios públicos se articulará en dos niveles:

a) El sistema de autoevaluación de los propios órganos y entidades dispensadores de los servicios.

b) El sistema de evaluación global sobre el conjunto de los servicios públicos de la Comunidad de Madrid.

\section{Artículo 9. Sistemas de autoevaluación.}

Los órganos y entidades incluidos en el ámbito de aplicación de este Decreto realizarán una autoevaluación de la calidad de sus prestaciones o servicios que comprenderá la medición de los niveles efectivos de prestación de sus servicios, teniendo como referencia el modelo de Calidad Total de la Fundación Europea para la Gestión de la Calidad (EFQM), y el seguimiento de la respectiva Carta de Servicios.

\section{Artículo 10. Medición de los niveles efectivos de prestación de los servicios.}

1. Papa realizar un diagnóstico del nivel de calidad con que se vienen prestando los servicios, sobre la base de los modelos enunciados en el artículo anterior, los órganos y entidades de la Administración autonómica delimitados en el artículo 2 implantarán sistemas de medición de acuerdo con los siguientes criterios:

a) Fijación de "valores-basen o estándares que sirvan como patrones de referencia objetivos y apropiados para cuantificar la evolución de los indicadores.

b) Selección de indicadores de calidad fiables y representativos de los parámetros o dimensiones de la prestación del servicio más relevantes para los usuarios, tales como:

- La receptividad (p. ej. accesibilidad, transparencia, atención). 
- La calidad técnica (p. ej. acierto, precisión, ausencia de errores).

- La actividad (p. ej. tiempos de respuesta, extensión oferta, flexibilidad).

- Otros aspectos específicos de cada servicio.

2. La evaluación de los niveles de calidad con que se dispensan los servicios incluirá datos sobre la satisfacción de los usuarios, que podrán obtenerse directamente a través de métodos de consulta o encuestación.

3. Anualmente se elaborará un informe sobre la evolución de los indicadores de calidad, que será remitido a la Dirección General de Calid de los Servicios a los efectos previstos en el artículo 12.

\section{Artículo 11. Seguimiento de las Cartas de Servicios.}

1. Los órganos y entidades a los que se refiere el presente Decreto remitirán con periodicidad anual a la Dirección General de Calidad de los Servicios un informe sobre el grado de cumplimiento de los compromisos declarados en la correspondiente Carta, analizando las eventuales desviaciones y determinando las medidas correctoras oportunas.

2. Tales medidas se instrumentarán de acuerdo con lo establecido en el artículo siguiente y serán tenidas en cuenta para la actualización de compromisos prevista en el apartado b) del artículo 4.2 de este Decreto.

\section{Artículo 12. Evaluación global del conjunto de los servicios públicos.}

Sobre la base de las autoevaluaciones remitidas por los distintos órganos y entidades así como de los informes relativos a reclamaciones y sugerencias recibidas, la Dirección General de Calidad de los Servicios presentará anualmente un Informe conteniendo una evaluación global de la calidad del conjunto de los servicios públicos.

\section{Artículo 13. Medición del indice de percepción de calidad del servicio.}

Sin perjuicio de lo previsto en el artículo anterior, la Dirección General de Calidad de los Servicios medirá periódicamente el índice de percepción de calidad del servicio, el cual proporciona el conocimiento del grado de satisfacción de los usuarios en relación con los servicios que presta la Comunidad de Madrid.

\section{Artículo 14. La Dirección General de Calidad de los Servicios.}

La Dirección General de Calidad de los Servicios desarrollará las siguientes funciones:

1. Impulsar, asesorar y apoyar a las unidades responsables en la elaboración y actualización de las Cartas de Servicios.

2. Llevar el registro de las Cartas de Servicios.

3. Colaborar con las unidades responsables de los distintos organismos y entidades en el diseño de los sistemas de autoevaluación a que se refiere el artículo 9.

4. Elaborar el Informe sobre el conjunto de los servicios públicos previsto en el artículo 12 .

5. Medir periódicamente el índice de percepción de calidad del servicio.

\section{CAPÍTULO IV}

\section{Premio anual a la excelencia y calidad del servicio público en la Comunidad de Madrid}

\section{Artículo 15. Creación.}

1. Se crea el Premio anual a la excelencia y calidad del servicio público en la Comunidad de Madrid, con el fin de premiar a los órganos y entidades dependientes de la Administración autonómica, que se hayan distinguido en la realización de actividades de mejora en la calidad del servicio ofrecido al ciudadano.

2. El premio se dirige especialmente a organizaciones del sector público tales como hospitales, clínicas, centros de atención al menor, residencias de personas mayores, albergues juveniles, oficinas de atención al ciudadano, escuelas y universidades, sin perjuicio de que puedan concurrir al premio cualquier otro órgano o entidad comprendidos dentro del ámbito de aplicación del preșente Decreto.

3. En la concesión del premio se tendrá en cuenta la calidad del servicio que una determinada organización ofrece a los ciudadanos y la opinión que éstos tienen como usuarios de dicho servicio, para lo cual se atenderá especialmente al resultado de las encuestas realizadas a los mismos.

4. La convocatoria del premio se hará con carácter anual, determinándose en la misma las bases por las que se habrá de regir su concesión, así como la composición del jurado que concederá el Premio, el cual estará presidido por el Presidente de la Comunidad de Madrid. 
Disposición Final Primera. Facultad de aplicación y desarrollo.

Se autoriza al Consejero de Hacienda para dictar cuantas disposiciones y medidas sean necesarias para la aplicación y desarrollo de este Decreto.

\section{Disposición Final Segunda. Entrada en vigor.}

1. El presente Decreto entrará en vigor el día siguiente al de su publicación en el "Boletín Oficial de la Comunidad de Madridn.

2. En el plazo de doce meses desde la entrada en vigor de esta disposición, los órganos y entidades comprendidos en su ámbito de aplicación elaborarán y aprobarán sus Cartas de Servicios.

Dado en Madrid, a 6 de marzo de 1997.
EL CONSEJERO DE HACIENDA, Antonio Beteta Barreda

EL PRESIDENTE Alberto Ruiz Gallardón bación de que las Cartas cumplen, al menos, con las previsiones de contenido mínimo que se efectúan en este Decreto. La otra función adicional se refiere a la divulgación del contenicho de las Cartas mediante su publicación en el Boletín Oficial de la Comunidad de Madrid. Esta publicación se efectuará mediante resolución de la Dirección General de Calidad de los Servicios, tras la remisión a ésta de la Carta de Servicios aprobada por resolución del titular del órgano o del máximo responsable de la entidad a cuyos servicios se refiere la Carta y es independiente de la publicación de la resolución de aprobación, ya prevista por el artículo 6 del Decreto 27/1997.

Por último, a pesar del grado de avance que se registra en el proceso de elaboración de las Cartas de Servicios por parte de numerosas unidades de la Comunidad de Madrid, es necesario que dicho avance se haga extensivo y culmine con la aprobación de las Cartas de Servicios de todas las unidades que prestan servicios directos a los ciudadanos, por lo que debe ampliarse en catorce meses el plazo de elaboración y aprobación de las Cartas de Servicios.

En su virtud, a propuesta del Consejero de Hacienda, y previa deliberación del Consejo de Gobierno de la Comunidad de Madrid, en su reunión del día

\section{DISPONGO}

\section{PREÁMBULO}

Mediante el Decreto 27/1997, de 6 de marzo, se regularon las Cartas de Servicios, los sistemas de evaluación de la calidad y los premios anuales a la excelencia y calidad del servicio público en la Comunidad de Madrid. En el actual estado del proceso de elaboración de Cartas de Servicios, por parte de las unidades prestadoras de servicios al ciudadano con el apoyo y asesoramiento de la Dirección General de Calidad de los Servicios, se ha puesto de manifiesto la necesidad de facilitar los trabajos de desarrollo del sistema de Cartas de Servicios en la Administración de la Comunidad de Madrid, a fin de que pueda implantarse en todo su ámbito de actuación respecto a los servicios prestados a los ciudadanos. A tal fin, este Decreto tiene por objeto, en primer término, fijar un contenido mínimo de las Cartas de Servicios y aprobar un modelo de ficha para su cumplimentación.

Por otra parte, se considera necesario atribuir dos funciones adicionales a la Dirección General de Calidad de los Servicios, al objeto de delimitar claramente, junto con las funciones ya atribuidas por el Decreto 27/1997, el marco de las actividades de asesoramiento y apoyo que dicha Dirección General realiza en materia de Cartas de Servicios. La primera de esas funciones adicionales es la emisión de informe favorable con carácter previo a la aprobación de las Cartas de Servicios, para la compro-
Artículo único.

Modificar el Decreto 27/1997, de 6 de marzo, por el que se regulan las Cartas de Servicios, los sistemas de evaluación de la calidad y los premios anuales a la excelencia y calidad del servicio público en la Comunidad de Madrid, en el sentido de añadir un nuevo artículo 4 bis, contenido mínimo y dos nuevos apartados, el 6. y el 7..., al artículo 14, funciones de la Dirección General de Calidad de los Servicios, quedando dichos preceptos redactados como sigue:

\section{Artículo 4 bis. Contenido minimo.}

En todo caso, el contenido mínimo de las Cartas de Servicios comprenderá:

a) Datos identificativos del órgano o entidad prestador del servicio: denominación, Consejería de adscripción responsable de la elaboración y gestión de la correspondiente Carta de Servicios, dirección, horario de atención al ciudadano, números de teléfono y de fax.

b) Principales servicios prestados.

c) Compromisos de calidad: objetivos e indicadores. 
d) Sistema de sugerencias y reclamaciones.

Como Anexo a este Decreto se publica el modelo de ficha de cumplimentación del contenido mínimo de las Cartas de Servicios.

Artículo 14.

6. Emitir informe favorable previo a la aprobación de las Cartas de Servicios.

7. Publicar el contenido de las Cartas de Servicios en el Boletín Oficial de la Comunidad de Madrid, tras su aprobación por el órgano competente, según el artículo 6.1 de este Decreto.

Disposición Final.

1. En el plazo de catorce meses desde la entrada en vigor de esta disposición, los órganos y entidades comprendidos en el ámbito de aplicación del Decreto 27/1997, de 6 de marzo, elaborarán y aprobarán sus Cartas de Servicios.

2. El presente Decreto entrará en vigor al día siguiente de su publicación en el Boletín Oficial de la Comunidad de Madrid.

EL CONSEJERO DE HACIENDA, Antonio Beteta Barreda

EL PRESIDENTE Alberto Ruiz Gallardón

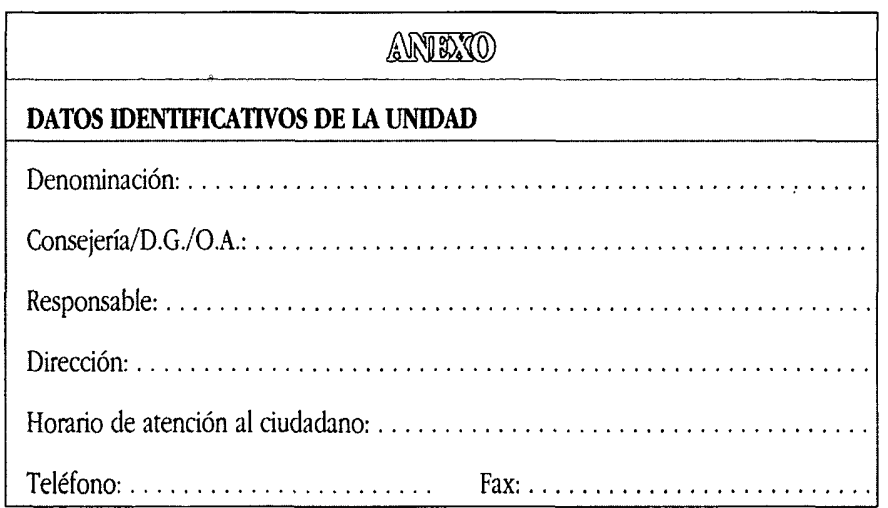

\section{PRINCIPALES SERVICIOS QUE PRESTA LA UNIDAD AL CIUDADANO}

\section{COMPROMISOS CON LOS CIUDADANOS}

Objetivos:

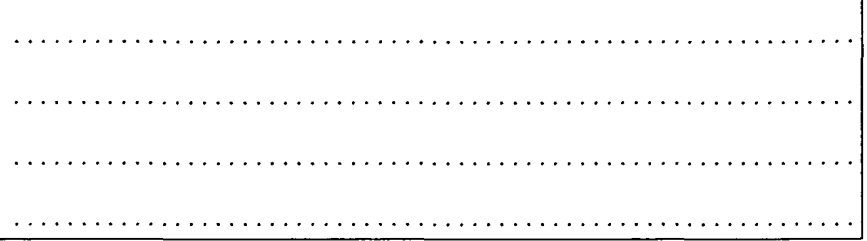

Indicadores:

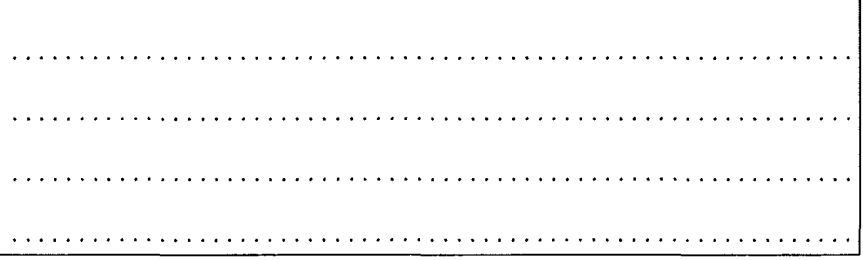

\section{Sugerencias y Reclamaciones}

Con el fin de mejorar la calidad de los servicios públicos prestados, la Comunidad de Madrid ha implantado un sistema de Sugerencias y Reclamaciones a través del cual los ciudadanos hacen llegar su opinión sobre los servicios prestados.

Las Sugerencias y Reclamaciones serán presentadas por personas físicas, que lo harán en su propio nombre o cn nombre de la entidad jurídica destinataria del servicio prestado.

Los principales centros administrativos cuentan con un impreso normalizado para la presentación de sugerencias y reclamaciones por medio de las cuales se puede ejercer ese derecho, si bien puede ser utilizado cualquier otro formato, siempre y cuando se presenten por escrito y firmadas.

Para que la Comunidad de Madrid puede ponerse en contacto y dar respuesta a la sugerencia o reclamación planteada, en los escritos de presentación deberán constar datos de contacto suficientes, siendo fundamental una dirección, un número de teléfono o, mejor, ambas cosas.

También es importante que quede perfectamente claro sobre qué se sugiere o reclama, por ello las Sugerencias y Reclamaciones deben tener carácter individualizado (deben referirse a casos concretos) no pudiendo hacerse denuncias genéricas.

Las Sugerencias y Reclamaciones pueden registrarse por cualquiera de los sistemas previstos en la Ley y, en consecuencia, pueden entregarse en cualquiera de los registros de la Comunidad, enviarse por correo o presentarse directamente en la Oficina de Atención al Ciudadano.

En un plazo aproximado de 48 horas la Comunidad se pondrá en contacto con el reclamante, por teléfono o por carta, y 
tratará de dar respuesta a la sugerencia o reclamación en un plazo no superior a 15 días.

A través de las Sugerencias y Reclamaciones de los ciudadanos, la Comunidad de Madrid detecta dónde se produce el mal funcionamiento de los servicios que presta. El sistema de Sugerencias y Reclamaciones de la Comunidad de Madrid permite saber dónde se debe mejorar.

\section{Orden 1417/1998, de 5 de junio, de la Consejeria de Hacienda, por la que se convoca el II Premio anual a la excelencia y calidad del servicio público en la Administración de la Comunidad de Madrid.}

\section{DISPONGO}

En desarrollo del Decreto 27/1997, de 6 de marzo, por el que se regulan las Cartas de Servicios, los sistemas de evaluación de la calidad y los premios anuales a la excelencia y calidad del servicio público en la Comunidad de Madrid, se convocó por Orden 1049/1997, de esta Consejería, el I de dichos Premios anuales. Con ello se pretendía, por una parte, premiar el esfuerzo y reconocer la mejora de los resultados alcanzada con la implantación de iniciativas de calidad, de las cuales son principales protagonistas los empleados públicos, que redundarán en la mejora de los servicios que presta la Comunidad a los ciudadanos. Además se perseguía el objetivo de divulgar el Modelo Europeo de Excelencia, elegido por la Administración de la Comunidad de Madrid como soporte de su sistema de calidad.

A la primera convocatoria del Premio se presentaron 26 candidaturas, que fueron valoradas en base a los criterios del Modelo Europeo de Excelencia por el Jurado constituido al efecto, integrado por representantes de organizaciones cuya característica común es la adopción de la Calidad Total como objetivo en un proceso de mejora continua, bajo la presidencia del Presidente de la Comunidad de Madrid. Tanto la presentación de un número significativo de candidaturas, tratándose de la primera edición del Premio, como el alto nivel puesto de manifiesto en los procesos de preselección y valoración no hacen sino corroborar el resultado positivo que se preveía iba a tener la convocatoria del Premio.

Dada la excelente acogida y los resultados obtenidos por la primera edición, procede convocar la segunda edición del Premio a la excelencia y calidad del servicio público en la Comunidad de Madrid 1998-99, manteniéndose la finalidad de la anterior, manifestada en un doble carácter, por una parte recompensar la mejora efectiva y comprobada en la prestación de los servicios al ciudadano por parte de las distintas unidades que componen la Administración de la Comunidad de Madrid, y además fomentar la implantación de proyectos de mejora cuyo beneficiario sea el ciudadano de la Co- munidad de Madrid, considerado como cliente de la misma y como fin último de su actividad.

Por parte de la Dirección General de Calidad de los Servicios de la Consejería de Hacienda se prestará el asesoramiento técnico que necesiten las unidades candidatas al Premio, fomentándose asimismo de esta manera la implantacion de proyectos de mejora y un mayor conocimiento, por parte de los gestores de los servicios públicos, de las técnicas y herramientas que sirven para alcanzar cotas de calidad cada vez más altas mediante un proceso de mejora continua que tenga por objetivo la excelencia de los servicios públicos que se prestan a los ciudadanos.

En base a lo expuesto,

\section{DISPONGO}

Artículo Único.

Se convoca la segunda edición de los Premios anuales a la excelencia y calidad del servicio público en la Comunidad de Madrid, con el fin de premiar a los órganos y entidades dependientes de la Administración de la Comunidad de Madrid que se hayan distinguido en la realización đe actividades de mejora en la calidad del servicio ofrecido al ciudadano, de acuerdo con las bases que se hacen públicas en el Anexo de la presente Orden.

Disposición Final.

La presente Orden entrará en vigor el día siguiente de su publicación en el Boletín Oficial de la Comunidad de Madrid.

Madrid, a 5 de junio de 1998.

Contra esta Orden podrá interponerse recurso contencioso administrativo ante el Tribunal Superior de Justicia de Madrid, en el plazo de dos meses a contar desde el día de su publicación en el Boletín Oficial de la Comunidad de Madrid.

\section{EL CONSEJERO DE HACIENDA, Antonio Beteta Barreda}

\section{Primera}

El premio se dirige especialmente a organizaciones del sector público de la Administración de la Comunidad de Madrid ta- 
les como hospitales, centros de salud, centros de atención a la mujer, centros de atención al menor, residencias de personas mayores, albergues juveniles, oficinas de atención al ciudadano, bibliotecas, escuelas, instalaciones deportivas, universidades, teatros y museos, sin perjuicio de que pueda concurrir al mismo cualquier otro órgano o entidad con rango mínimo de Servicio de los comprendidos dentro del ámbito de aplicación del Decreto 27/1997, de 6 de marzo, por el que se regulan las Cartas de Servicios, los sistemas de evaluación de la calidad y los premios anuales a la excelencia y calidad del servicio público en la Comunidad de Madrid.

\section{Segunda}

1. El premio consistirá en un certificado firmado por el Presidente de la Comunidad de Madrid.

2. Se otorgarán menciones especiales del Premio y/o diplomas de finalista a las candidaturas mejor valoradas tras la ganadora.

3. Se podrán otorgar diplomas de reconocimiento a la iniciativa de calidad en el servicio público a las candidaturas que el Jurado considere merecedoras de tal reconocimiento.

\section{Tercera}

1. Las candidaturas se dirigirán a la Dirección General de Calidad de los Servicios de la Consejería de Hacienda y podrán ser presentadas en el Registro de la Consejería de Hacienda en la Plaza de Chamberí número 8 , o mediante cualquiera otra de las formas previstas en el artículo 38.4 de la Ley 30/1992, de 26 de noviembre, de Régimen Jurídico de las Administraciones Públicas y del Procedimiento Administrativo Común.

2. El plazo de presentación finalizará el 15 de noviembre de 1998.

\section{Cuarta}

1. Las candidaturas deberán formularse en el modelo que figura como Anexo I a las presentes Bases y deberán ir firmadas por el Director General o Gerente responsable de la unidad candidata al premio, así como ir acompañadas de toda la documentación que acredite la realidad de los hechos y circunstancias declaradas para optar al premio de acuerdo con los criterios establecidos en la basse quinta.

2. Por parte de las unidades interesadas en ser candidatas al premio podrá solicitarse, con carácter previo a su presentación al mismo, el asesoramiento de la Dirección General de Calidad de los Servicios de la Consejería de Hacienda a fin de poder completar los extremos que serán objeto de consideración para la concesión del premio según lo dispuesto en la base quinta.

3. Si las solicitudes no vinieran acompanadas de la documentación prevista en la presente Orden, se requerirá a los solicitantes para que en el plazo máximo de 20 días se proceda a subsanar los defectos observados, apercibiéndoles de que, de no hacerlo así, se procederá a su exclusión como candidatos.

\section{Quinta}

Se establecen dos fases para la concesión del premio: una primera de preselección de unidades candidatas, la cual será realizada por la Dirección General de Calidad de los Servicios, y una segunda de valoración de las candidaturas preseleccionadas y de concesión del premio, la cual será realizada por un Jurado.

Sexta

Las candidaturas podrán optar por uno de los dos siguientes procedimientos de preselección que se exponen a continuación:

A) La Dirección General de Calidad de los Servicios tendrá en cuenta los siguientes aspectos referidos a la unidad candidata al premio:

- Que ha definido normas y objetivos de funcionamiento del servicio que presta.

- Que informa a los ciudadanos en general y a sus usuarios en particular de cuáles son esas normas y si las cumple normalmente.

- Que informa a los ciudadanos acerca de todos los servicios y la ayuda de que pueden disponer por parte de su organización.

- Que pregunta a sus clientes acerca de qué servicios necesitan y cómo piensan que pueden mejorar.

- Que hace buen uso de las ideas que le hacen llegar quienes utilizan sus servicios.

- Que da a los usuarios la posibilidad de escoger siempre que esto sea posible.

- Que el personal que atiende las necesidades de sus clientes es educado y atento.

- Que facilita a los ciudadanos la presentación de sus reclamaciones y sugerencias.

- Que actúa rápidamente para solucionar los problemas que puedan surgir. 
- Que valora el dinero y gasta cuidadosamente los fondos públicos.

- Que está comprometido con la mejora de la calidad de sus servicios y tiene nuevas ideas para seguir mejorando en el futuro.

- Que los ciudadanos reconocen que realmente les ofrece un buen servicio y se sienten "verdaderos clientes" de su organización.

B) La Dirección General de Calidad de los Servicios realizará una encuesta-evaluación basada en el Modelo Europeo de Excelencia, que someterá a la cumplimentación de una muestra del personal de la unidad candidata, y cuyos resultados serán tenidos en cuenta para la preselección. La unidad candidata que opte por este procedimiento de preselección deberá adjuntar a la solicitud de presentación al Premio relación nominal del personal funcionario de nivel 25 o superior y personal laboral con categoría de nivel igual o superior a la de Titulado Medio, así como número al que asciende el restante personal de la unidad.

\section{Séptima}

Dentro de la fase de valoración de las candidaturas preseleccionadas y de concesión del premio el Jurado tendrá en cuenta las ideas de mejora implantadas por las unidades candidatas referidas como mínimo a uno de los nueve criterios que se relacionan a continuación, dentro del marco del Modelo Europeo de Excelencia de la Fundación Europea para la Gestión de la Calidad. Estas ideas de mejora se presentarán en una memoria suscrita por el Director General o Gerente de la unidad candidata al premio, y su extensión máxima será de diez páginas, a doble espacio.

Los extremos contenidos en la citada memoria podrán ser objeto de comprobación y/o aclaración por parte de la Dirección General de Calidad de los Servicios.

\section{CRITERIO 1. Liderazgo}

Subcriterios:

1.a) Cómo los directivos demuestran de manera visible su compromiso con la filosofía de la Gestión de Calidad Total.

1.b) Cómo los directivos apoyan la mejora y la involucración proporcionando los recursos y la ayuda adecuados.

1.c) Cómo los directivos se involucran con clientes, proveedores y otras organizaciones externas. 1.d) Cómo los directivos reconocen y aprecian los esfuerzos y logros del personal.

\section{CRITERIO 2. Politica y estrategia}

\section{Subcriterios:}

2.a) Cómo la política y estrategia de la organización se basa en información relevante y global.

2.b) Cómo se desarrolla la política y estrategia de la organización.

2.c) Cómo se comunica e implanta la política y la estrategia de la organización.

2.d) Cómo se actualiza y mejora periódicamente la política y la estrategia de la organización.

\section{CRITERIO 3. Gestión del personal}

Subcriterios:

3.a) Cómo se planifican y mejoran los recursos humanos.

3.b) Cómo se mantienen y desarrollan las capacidades del personal.

3.c) Cómo se acuerdan los objetivos del personal y se revisa continuamente su rendimiento.

3.d) Cómo se implica, faculta y reconoce al personal.

3.e) Cómo existe un diálogo eficaz entre el personal y la organización.

3.f) Cómo cuida la organización a sus empleados.

\section{CRITERIO 4. Recursos}

Subcriterios:

4.a) Cómo se gestionan los recursos económicos y financieros.

4.b) Cómo se gestionan los recursos de información.

4.c) Cómo se gestionan los materiales y las relaciones con los proveedores.

4.d) Cómo se gestionan los edificios, materiales y otros bienes.

4.e) Cómo se gestionan la tecnología y la propiedad intelectual. 
CRITERIO 5. Procesos

Subcriterios:

5.a) Cómo se identifican los procesos críticos para el éxito de la organización.

5.b) Cómo se gestionan los procesos de manera sistemática.

5.c) Cómo se revisan los procesos y se establecen objetivos de mejora.

5.d) Cómo se mejoran los procesos mediante la innovación y creatividad.

5.e) Cómo se modifican los procesos y se evalúan las ventajas que de ello se derivan.

\section{CRITERIO 6. Satisfacción del cliente}

Subcriterios:

6.a) La percepción que los clientes tienen de los productos, servicios y relaciones de la organización con ellos.

6.b) Mediciones complementarias relativas a la satisfacción de los clientes de la organización.

\section{CRITERIO 7. Satisfacción del personal}

Subcriterios:

7.a) La percepción que los empleados tienen de su organización.

7.b) Mediciones complementarias relacionadas con la satisfacción del personal.

\section{CRIT'ERIO 8. Impacto en la Sociedad}

Subcriterios:

8.a) Cómo percibe la sociedad a la organización.

8.b) Mediciones complementarias relativas al impacto de la organización en la sociedad.
CRITERIO 9. Resultados

Subcriterios:

9.a) Mediciones de carácter económico del rendimiento general de la organización.

9.b) Mediciones complementarias del rendimiento general de la organización.

Tanto la fase de preselección como la de valoración concluirán antes del 15 de enero de 1999.

\section{Octava}

Según el artículo 15.4 del Deereto 27/1997, de 6 de marzo, el Jurado se halla presidido por el Presidente de la Comunidad de Madrid. En la presente convocatoria se hallará integrado en cuanto a sus restantes miembros por cuatro Vocales y un Secretario que será el Director General de Calidad de los Servicios de la Consejería de Hacienda y se constituirá antes del 5 de enero de 1999.

Una vez determinada la composición del Jurado de candidaturas será publicada en el Boletín Oficial de la Comunidad de Madrid.

\section{Novena}

- El fallo será inapelable y se dará a conocer antes del 10 de febrero de 1999, publicándose en el Boletín Oficial de la Comunidad de Madrid. La entrega de premios se realizará en la fecha y lugar que en su momento se dé a conocer.

- Las unidades ganadoras del premio tendrán derecho a usar el logotipo del mismo durante tres años, después de este plazo necesitarán volver a presentarse al mismo y obtenerlo para poder seguir usándolo.

- Si a juicio del jurado ninguna candidatura reuniera los méritos suficientes para ser galardonada con el premio, éste será declarado desierto.

\section{Décima}

La presentación de propuestas supone la aceptación de las presentes bases.

\section{Notas}

Licenciado en Ciencias Económicas y Empresariales (ICADE E-2). Director General

de Calidad de los Servicios de la Comunidad de Madrid. 
s. 